\section{POPULATION'S DYNAMIC SIMULATOR}

\section{Morando L. IDIP Hospital de Niños de La Plata, Argentina.}

Introduction: Many adaptive systems are difficult to analyze and to control using traditional techniques. Aims: In this work, we introduce a computerized tool to study agents having a life cycle, which evolve through time, and are subject to stochastic events. Methods: We used population' dynamic techniques and the high capability of computer systems to process data to build a simulator, which was developed using techniques based on evolution and adaptation of the best, known as genetic algorithms, introducing stochastic methods to model situations where the occurrence of events has a given probability distrib environmental properties, to define the genotype information for each type of agent, and to include the rules to confer the phenotype. Also, it is possible to shape several aspects like the main data of the life cycle of the agents. Results: With all the data, the soft has an initial population with a required amoun of agents and simulates the population's development across the time. For each interval of time it is possible to observe the population's density, to analyze the genetic evolution and to extract statistica data about the main characteristics of each agent. Comments: This tool is appropriate to simulate epidemiological events, because it is possible to simulate the development of one or more populations under different environments and conditions, during different intervals of time. It is also useful to identify the main features that may alter the system.

\section{0}

INFANT MORTALITY: ANALYSIS OF THE SOCIAL AREA AND REDIRECTION OF HEALTH SYSTEMS TOWARDS EQUITY

Rubio AM, Stival J, Etchegoyen G*. Dirección de Medicina Preventiva de la Municipalidad de Córdoba. *Instituto de Desarrollo e Investigaciones Pediátricas (IDIP) . Hospital de Niños "Sor María Ludovica" de La Plata

INTRODUCTION: Beyond the impact of implementing public health actions focused on motherand-child health, there are doubts about whether they actually meet the different levels of need within and across population. This poses the need to work on some criteria based on the population's socio-demographic features according to a social area. That social area, built by human groups, articulates with the economic framework of production processes. This opens a new approach to health problems. OBJECTIVE: to analyze health status in the 14 social areas in the city of Cordoba Argentin. Its purpose is to direct health systems towards equity by means of an effich resources. METHODOLOGY: This geo-socially referring survey analyzes the infant mortality rate and its links with poverty -as indicated by the percentage of population with unsatisfied basic needs (UBN) and the offer of health services. Information from each social area was obtained from the governmen office of Preventive Medicine (Municipality of Córdoba), and was stored in a specially designed database. Statistical analyses were performed by the Public Health Statistics Program EpiInfo 6. RESULTS: The results achieved show that poverty level was $15.6 \%$ in the whole city, varying from $0 \%$ to $25 \%$ in the different social areas. Infant mortality rate in Cordoba was $15.9 \%$ presenting wide variations within each social area. Nevertheless, mortality rates did not significantly correlate either with the different levels of poverty or with the offer of health services. Evenmore, social areas with a similar percent of population with UBN $(17.6 \%$ and $18.6 \%)$ showed quite different infant mortality rates $\left(31.7^{0} \%\right.$ and $18 \%$ \% $)$. On the other hand, social areas with extreme poverty level values $(0 \%$ an $25 \%$ of population with UBN) showed similar infant mortality rates $(18 \%$ and $17.6 \%$ ). CONCLUSION: Although our results are preliminary and need a further investigation involving other health-related aspects, such as social capital, they will allow to redirect local policies: "know-how", "what-to-do" and especially "where-to-do".

\section{1}

\section{COMPARISON OF FORCED OSCILLATION TECHNIQUE AND SPIROME- TRY FOR ASSESSING AIRWAY OBSTRUCTION AND ITS REVERSIBILITY IN ASTHMATIC CHILDREN}

Colom A, Navarra F, Andrada G, Kofman C, Teper A. Centro Respiratorio, Htal. de Niños R. Gutiérrez, Buenos Aires, Argentina.

The forced oscillation technique (FOT) is particularly attractive for pediatric use as this requires only passive cooperation from the patient. This technique allows to measure respiratory resistance $(R)$ and calculate lung compliance (C). The aim of the study was to evaluate the correlation between spirometry and FOT, and compare the sensitivity and specificity of the different parameters to asses the reversibility of the airway, in asthmatic children. Spirometry and FOT were performed correlatively, and bronchodilator response (BDR) was evaluated $30 \mathrm{~min}$ after the inhalation of $200 \mathrm{mcg}$ salbutamol. A $10 \%$ increase in $\mathrm{FEV}_{1}$ was considered positive. We used Vmax sensor medics device. Inclusion criteria were: diagnosis of asthma, older than 5 years old, capable of performing PFT's. 39 children were included, 18 male, mean age 10 years (range 5-17). Results of basal spirometry were as children were included, 18 male, mean age 10 years (range 5-17). Results of basal spirometry were as
follows, expressed as $\%$ of theoretical value (mean \pm SD): FVC $100 \pm 17 \%$, FEV $195 \pm 20 \%$, follows, expressed as \% of theoretical value (mean \pm SD): FVC $100 \pm 17 \%, \mathrm{FEV}_{1} 95 \pm 20 \%$,
$\mathrm{FEF}_{25-75} 83 \pm 32 \%$ and FOT: $\mathrm{R}_{4-16} 170 \pm 47 \%, \mathrm{R}_{0} 178 \pm 57 \%$ and Compliance $69 \pm 31 \%$. The correlation between FOT and spirometry were: 0.71 (IC -0.84 to -0.5 ) for $\mathrm{FEV}_{1} \& \mathrm{R}_{4-16}, 0.73$ (IC -0.85 to -0.54 ) for $\mathrm{FEV}_{1} \& \mathrm{R}_{0}, 0.76$ (IC 0.58 to -0.87 ) for $\mathrm{FEV}_{1} \& \mathrm{C}$ and lower when we compared FOT with $\mathrm{FEF}_{25-75}$. The best cut off to discriminate between positive and negative BDR was $20 \%$ of postbronchodilator changes in $\mathrm{R}_{4-16}$, with $59 \%$ specificity and $73 \%$ sensitivity, and $30 \%$ in $\mathrm{R}_{0}$, with $73 \%$ specificity and $64 \%$ sensitivity. Spirometry and FOT have a good correlation in asthmatic children, and FOT has acceptable sensibility for BDR diagnosis.
SEXUAL DIMORPHISM IN BODY COMPOSITION IN BRAZILIAN SCHOOL CHILDREN FROM 1979/80 TO 1993/94

Zambon MP ${ }^{1}$, Marmo DB ${ }^{1}$, Morcillo $\mathrm{AM}^{1}$, Guimarey $\mathrm{LM}^{2}{ }^{1}$ universidade Estadual De Campinas (Unicamp). Brazil. ${ }^{2}$ Comision De Investigaciones Cientificas, Provincia De Bsas (Cic). Argentina

Nutritional stress can be seen in several catastrophic events like wars and when socio-economic differences are very important. Nutritional stress can affect growth and development, changing body composition and minimizing sexual dimorphism. Background: The purpose of this study was to upper arm muscle area (UAMA) in school children from Paulñnia, S $\gamma_{0}$ Paulo, Brazil between 1979/80 and 1993/94, periods in which the city had good development, low under nutrition rate and positive growth secular trends. Material and methods: BMI, UAC, UAFA and UAMA were calculated for 2098 children (age range $6.5-10.5 \mathrm{yr} ; 540$ (310M:230F) in 1979/80 and 1558 (865M:693F) in 1993/94. Sexual dimorphism was measured by relative differences between means with the formula: DS $=$ $(50 *(\mathrm{x} 1-\mathrm{x} 2)) /(\mathrm{x} 1+\mathrm{x} 2)(\mathrm{SD} 1+\mathrm{SD} 2)$, where: $\mathrm{x} 1=$ mean for males, $\mathrm{x} 2=$ mean for females, $\mathrm{SD} 1=$ standard deviation for males and SD2 = standard deviation for females. Results: Sexual dimorphism showed similar BMI, but UAC and UAFA that were higher in boys in the first study became lower in the second one. These changes were more significant in UAFA. UAMA data were similar in both sexes in the first study and became higher in males in the second one. Conclusions: These trends showed a recovery in sexual dimorphism. Girls recovered fat mass and boys got muscle mass in a lower degree.

\section{3}

ASSESSING SEVERE MALNUTRITION IN BOLIVIAN CHILDREN. KWASHIORKOR IN LATIN AMERICA?

Weisstaub SG ${ }^{1}$, Soria $\mathrm{R}^{2}$, Araya $\mathrm{M}^{1} .{ }^{1}=\mathrm{INTA}$, $\mathrm{U}$ de Chile, Stgo, Chile. ${ }^{2}=$ Centro de Pediatría "Albina R. de Patiño", Cochabamba, Bolivia.

Introduction. Malnutrition (MN) has decreased globally, but there are areas in Latin America where it continues being a significant health problem. In Bolivia $\mathrm{MN}$ is prevalent and there is no information about Kwashiorkor (Kw), a clinical presentation with high mortality rate. Objective: To characterize MN among children admitted to Centro de Pediatría "Albina R. de Patiño" (Cochabamba, Bolivia) for severe MN. Methods: longitudinal, descriptive assessment of relevant clinical data from all children admitted for severe MN during 2000-2001. Data were obtained from clinical records. Results. Of 2493 admissions in 2000/2001, 120 were severely malnourished children; two cases were excluded because their MN was secondary to other conditions. Therefore, 118 cases were analyzed (F/M. 56/62). Edematous forms of MN and Kw were more frequent ( $90 \%$ of cases) and occurred at older ages (median 15.2 in Kw vs 9.7 months in marasmus; $\mathrm{p}<0.01$, KWallis). On admission, $40 \%$ of children with $\mathrm{Kw}$ were above $-2 \mathrm{SD}$ for W/A. 61 patients were dehydrated; in $26 \%$ of them dehydration was severe $(\geq 10 \%)$ and $7 \%$ were in shock (total $=20$ cases). Total hospital mortality rate for the analyzed period was $5.2 \% .24$ of the 118 children admitted for severe MN died (20.3\%); of those admitted with severe dehydration $(n=20), 45 \%$ died $(n=9)$. The most frequent causes of death were sepsis $(n=14)$ and respiratory infections $(n=7)$. More than $50 \%$ of deaths occurred within 48 hours of admission. The main risk factors for death were low albumin $(<2 \mathrm{~g} / \mathrm{dL})$, pneumonia on admission, sepsis, severe dehydration and $\mathrm{W} / \mathrm{L}<-2 \mathrm{SD}$. Risk of death among patients admitted for severe MN was four times greater than in the rest of children admitted in the period $(\mathrm{OR}=4.8$, CI $2.87-7.98, \mathrm{p}<0.001)$ Conclusions. Edematous forms of MN were prevalent among children admitted for severe primary MN and they weighed considerably on mortality. For successful nutritional interventions it is crucial to incorporate to the analysis children with severe MN plus edema, which are missed by anthropometric standards. We propose to incorporate in hospital and primary health care statistics the presence absence of edema as criterion to define and register the condition. 